\section{Conversion of Pipet-Tip Boxes into Secure Storage Containers for Microcentrifuge Tubes}

BioTechniques 20:812 (May 1996)

We describe an inexpensive and convenient container that solves some common problems associated with storing microcentrifuge tubes in refrigerators and freezers. It is made from a plastic box that comes prepackaged with pipet tips, and we have used FISHERbrand ${ }^{\circledR}$ Redi-Tip boxes Catalog No. $21-197-8 \mathrm{H}$ (size $200 \mu \mathrm{L})$ or Catalog No. 21-197-2E (size 0.5-10 $\mu \mathrm{L}$ ) (Fisher Scientific, Pittsburgh, PA, USA) with equal success. When complete, each container will hold $24 \mathrm{mi}$ crocentrifuge tubes. The unit has an attached lid, which snaps shut so that the enclosed tubes will not dislodge from their original positions when the unit is turned upside down. Furthermore, the container can be labeled on all sides for easy identification, its contents can be clearly viewed through the transparent lid and multiple units can be neatly stacked. By using simple tools, a container can be manufactured in minutes from materials that would normally be discarded. The operation requires a metal core borer with a diameter slightly larger than that of the tubes to be stored (we use a 12-mm-diameter cork borer), a heat source such as a Bunsen burner, a pair of tweezers to remove excised pieces of plastic and a hood in which to melt the plastic since this can generate some toxic fumes.

The procedure is simply to excise the appropriately sized pieces of plastic in the inner white support rack at regularly spaced intervals by applying the heated end of the metal cork borer to the plastic rack. Starting at the upper left-hand corner of the rack and having the cork borer heated to a red-hot stage, we push the heated tool quickly into the support, centering the punch within the first 4 holes in the rack. Then we use tweezers to pull the plastic from the cork borer, reheat if necessary and punch the next hole. Repeating this procedure, 4 rows of 6 holes for $1.5-\mathrm{mL}$ or 2.0-mL tubes can be produced in a few minutes. For 0.5-mL tubes, either melt smaller holes with a smaller diameter borer or convert larger holes by covering them with a piece of tape and cutting an " $X$ " into the tape to support the smaller tubes.

By producing these secure and adaptable containers, we recycle plastics that would otherwise get thrown into the landfill, and we optimize freezer and refrigerator storage space in a very cost-effective manner.

This work was supported by a grant from the National Institutes of Health (CA60250). Address correspondence to William J. Hendry III, Department of Biological Sciences, Wichita State University, 1845 Fairmount, Wichita, KS 67260-0026, USA.

Received 30 November 1995; accepted 13 December 1995.

\section{Isabel R. Hendry and William J. Hendry III Wichita State University Wichita, KS, USA}

\section{Screening for Recombi- nant Plasmids in Yeast Colonies of the Two-Hy- brid System Using PCR}

\author{
BioTechniques 20:812-816 (May 1996)
}

The two-hybrid system $(2,5)$ is an ingenious tool to detect protein-protein interactions. A number of gene products could be confirmed to be actual interacters $(1,7,8)$, where others were identified by using cDNA libraries $(4,6,9)$. For any purpose it is necessary to clone the genes/gene repertoirs of the "query" protein and its putative partner(s) in two special plasmids, pGAD424 and pGBT9, respectively. Plasmids with correct inserts are transferred into yeast cells (strain HF7c), selected for several days on appropriate plates and then assayed for reporter

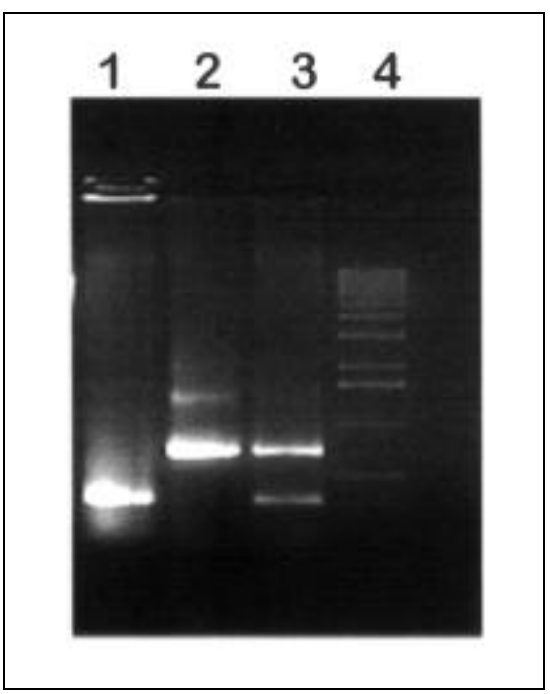

Figure 1. Demonstration of PCR of a selected yeast colony after directly lysing the cells and amplifying the plasmid DNA. PCR was routinely performed for 60 cycles, cycle program: $30 \mathrm{~s}$ at $94^{\circ} \mathrm{C}, 30 \mathrm{~s}$ at $54^{\circ} \mathrm{C}$ and $30 \mathrm{~s}$ at $72^{\circ} \mathrm{C}$ plus 1 -second per cycle. The products were analyzed by electrophoresis in $1 \%$ agarose/ethidium bromide. The following primers were used: A: 5'-CGCGTTTGGAATCACTACAGG-3' (primer for vector pGAD424), B: 5'-GCGACATCATCATCGGAAGA-3' (primer for vector pGBT9) and C: $5^{\prime}-\mathrm{GC}-$ ATGCCGGTAGAGGTGT-3' (common backprimer). Lane 1 shows the reaction product using primers $\mathrm{B}$ and $\mathrm{C}$, lane 2 shows the reaction products using primers $\mathrm{A}$ and $\mathrm{C}$ and lane 3 shows the reaction products using primers $\mathrm{A}, \mathrm{B}$ and $\mathrm{C}$. Lane 4 contains the 1-kb ladder (Life Technologies, Gaithersburg, MD, USA). 